\title{
Estimation of Abamectin Residues Present in Tea: High-Performance Liquid Chromatography Technique
}

\author{
Madasamy Kottiappan, Shanmugaselvan Veilumuthu Anandhan, \\ and Selvaganapathi Chandran
}

UPASI Tea Research Foundation, Tea Research Institute, Coimbatore District, Valparai, 642127 Tamil Nadu, India

Correspondence should be addressed to Madasamy Kottiappan; jey.sub11@gmail.com

Received 19 February 2013; Accepted 19 March 2013

Academic Editors: J.-F. Jen, A. I. Suarez, and A. Vazquez

Copyright (C) 2013 Madasamy Kottiappan et al. This is an open access article distributed under the Creative Commons Attribution License, which permits unrestricted use, distribution, and reproduction in any medium, provided the original work is properly cited.

\begin{abstract}
A simple, reliable, and sensitive method was based on high-performance liquid chromatography (HPLC) was developed and validated for the estimation of abamectin residues present in tea. The abamectin residues extracted with acetone-water mixture $(70: 30, \mathrm{v} / \mathrm{v})$ and derivatised with 1-methylimidazole (1-MIM) and trifluoroacetic anhydride (TFAA) were estimated by HPLC using fluorescence detector (FLD). The technique was validated in terms of linearity, precision, recovery, specificity, limit of detection (LOD), and limit of quantification (LOQ). A good linear relationship $\left(r^{2}>0.99\right)$ was absorbed in the abamectin concentration range from 0.01 to $1.0 \mu \mathrm{g} \mathrm{mL}^{-1}$. The limit of detection and limit of quantification of the method were 0.01 and $0.02 \mu \mathrm{g} \mathrm{g}^{-1}$, respectively. The average recoveries of the pesticide from black tea and dried green leaves ranged from 83.3 to $103.8 \%$ and 83.8 to $98.0 \%$, respectively.
\end{abstract}

\section{Introduction}

Tea, one of the oldest and most popular beverages in the world, is obtained from the tender leaves of the plant Camellia sinensis (L).O. Kuntze. South India, a major contributor to the global production of tea, continues to be the leader in national tea production contributing about $25 \%$ in toto and has the largest domestic market [1]. In order to improve the productivity and protect the tea plants from the harmful pests like mite, the acaricides are being applied on the canopy and/or tea bushes being with chemical spray. As a result, residue level of the acaricide present in the consumable tea is of considerable importance. Therefore, development of a highly reliable method is critical for the estimation of the acaricide residues present in tea.

Abamectin, which belongs to the macrocyclic lactone class of avermectins, is composed of at least $80 \%$ of avermectin $\mathrm{B}_{1 \mathrm{a}}$ and less than $20 \%$ of avermectin $\mathrm{B}_{1 \mathrm{~b}}$ (Figure 1 ), is produced by the actinomycetes (Streptomyces avermitilis) [2]. Because of its high toxicity to agricultural pests abamectin is widely used to control insects and mites in tea, vegetables, and fruits [3]. Abamectin present in various biological matrices including animal tissues, serum, fruits, and vegetables can be successfully determined by high-performance liquid chromatography (HPLC) in the reverse phase mode, coupled with different detectors, namely, ultraviolet detection (UVD), fluorescence detection (FLD), and mass spectrometry (MS) [3-5]. However, there is no report in the literature on the methodology for the determination of abamectin residues present in tea. Since the concentration of abamectin residues is very low, the UVD is less sensitive than FLD in determining the residues of abamectin closer to EU MRL values $\left(0.02 \mu \mathrm{g} \mathrm{g}^{-1}\right)$ for tea and MS is inaccessible for most of routine laboratories due to its high cost. A new analytical method has been attempted for the determination of abamectin present in tea. The method has been developed not only to achieve high sensitivity but also to provide reliability of determination and readiness for the routine analysis of abamectin residues present in tea. 


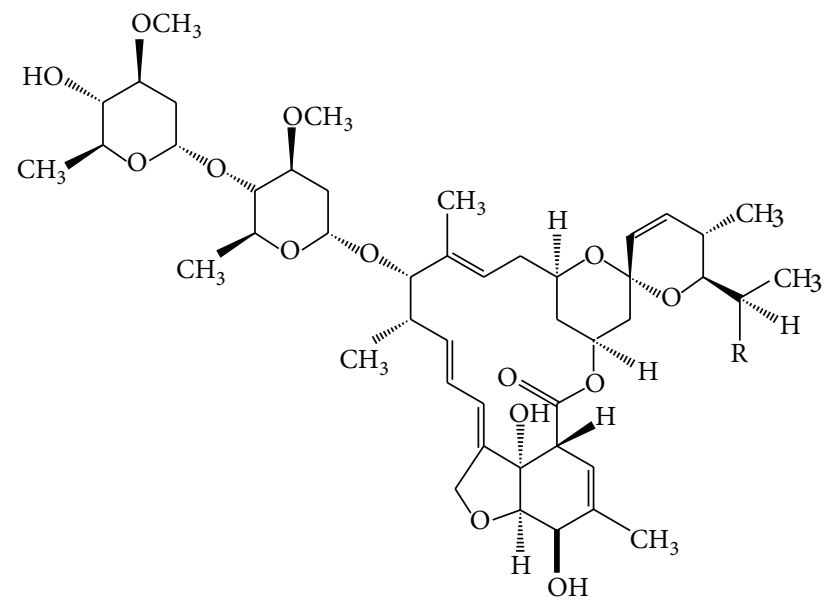

(i) $\mathrm{R}=-\mathrm{CH}_{2} \mathrm{CH}_{3}$ (avermectin $\mathrm{B}_{1 \mathrm{a}}$ )

(ii) $\mathrm{R}=-\mathrm{CH}_{3}$ (avermectin $\mathrm{B}_{1 \mathrm{~b}}$ )

FIGURE 1: Structure of abamectin.

\section{Materials and Methods}

2.1. Chemicals and Reagents. Technical standard (purity: 98.7\%) of abamectin was purchased from Sigma Aldrich (Bangalore, India). Analytical grades of acetone, dichloromethane, sodium chloride, and anhydrous sodium sulphate and HPLC grade of acetonitrile were purchased from $\mathrm{M} / \mathrm{s}$. Ranbaxy chemicals, New Delhi. Florisil (60-100 mesh) was purchased from M/s. Sisco Research Laboratories, Mumbai. A rotary mechanical shaker (REMI RS 36), a rotary vacuum evaporator (Labserve Super fit PBU6), millipore (Millipore Direct Q3 smart), sonicator, and glass column (20 mm dia, $590 \mathrm{~mm}$ length) were also used in the present study.

2.2. Preparation of Tea Samples. About $3 \mathrm{~kg}$ of green tea shoots (two leaves and a bud) were harvested from the field, half of the quantity was dried in shade for about a week and the remaining quantity was processed in the minimanufacturing unit, using the conventional CTC (Crush, Tear, and Curl) tea manufacturing process. The manufacturing process, in brief, involved withering of shoots (50-55\% water loss) at ambient temperature for $15-20 \mathrm{~h}$, rolling using a rotorvane for about $15 \mathrm{~min}$ with pressure, followed by fermentation (oxidation for $1-2 \mathrm{~h}$ at $25-30^{\circ} \mathrm{C}$ and $95 \% \mathrm{RH}$ ), and drying in a dryer, using hot air at $100 \pm 5^{\circ} \mathrm{C}$. The final moisture content of tea was $2-3 \%$. The matrices used for the study were the dried green leaves and black tea.

2.3. Standard Solution. A stock solution of abamectin of concentration $1000 \mu \mathrm{g} \mathrm{mL}^{-1}$ was made in acetonitrile. Working solutions of concentrations in the range $0.01-1.0 \mu \mathrm{g} \mathrm{mL}^{-1}$ were prepared by dilution in series of the stock solution with acetonitrile. The standards were stored at $-20^{\circ} \mathrm{C}$ and protected from light.

\subsection{Sample Preparation}

2.4.1. Fortification. Prior to extraction, $10 \mathrm{~g}$ of homogenized samples of black tea/dried green leaves were spiked by adding the standard solution to give fortification levels of 0.02 and $0.2 \mu \mathrm{gg}^{-1}$. To ensure good contact of the analytes with the whole sample, the mixture was equilibrated by shaking for $10 \mathrm{~min}$ and then left for three hours.

2.4.2. Extraction and Cleanup. Ten gram of black tea/dried green leaves sample were extracted with $200 \mathrm{~mL}$ of acetonewater mixture $(70: 30, \mathrm{v} / \mathrm{v})$ thrice by shaking it in a mechanical shaker for 2 hours [3]. The contents were filtered and collected. The pooled extract was partitioned with $100 \mathrm{~mL}$ of dichloromethane (DCM) and lower organic layer was collected in a $500 \mathrm{~mL}$ round bottomed flask (RBF) through anhydrous sodium sulphate. To the separate funnel containing aqueous layer, $50 \mathrm{~mL}$ of saturated $\mathrm{NaCl}$ solution and $50 \mathrm{~mL}$ of DCM were added and shaken vigorously. Again the lower organic layer was collected through anhydrous sodium sulphate in the RBF. The above process was repeated with another $50 \mathrm{~mL}$ of DCM. The combined DCM extracts were evaporated to dryness. The concentrated residue is reconstituted with $10 \mathrm{~mL}$ of DCM and transferred to a glass column packed with activated florisil $(10 \mathrm{~g})$ guarded with $1 \mathrm{~cm}$ of anhydrous sodium sulfate. Prior to elution, the column was washed with $50 \mathrm{~mL}$ of DCM to remove the coextractives and eluted with $150 \mathrm{~mL}$ of $2: 1$ acetone-chloroform mixture. The collected elute was concentrated to dryness.

2.4.3. Precolumn Fluorescence Derivatization. The residue was reconstituted with $5.0 \mathrm{~mL}$ of acetonitrile and $1.0 \mathrm{~mL}$ of this solution was transferred into a $5 \mathrm{~mL}$ test tube. Then $0.5 \mathrm{~mL}$ of 1 -methylimidazole-acetonitrile $(1: 1, \mathrm{v} / \mathrm{v})$ and $0.5 \mathrm{~mL}$ of trifluoroacetic anhydride-acetonitrile $(1: 2, \mathrm{v} / \mathrm{v})$ mixture were added to the test tube. The test tube was incubated at $60^{\circ} \mathrm{C}$ for 3 hours. After incubation the residue was determined by HPLC with fluorescence detector.

2.5. HPLC-FLD Analysis. Chromatographic analysis was performed using Agilent 1100 series (Chemstations) equipped with fluorescence detector. The chromatographic separation was performed on a Zorbax Rx C18 $(250 \mathrm{~mm} \times 4.6 \mathrm{~mm} \times$ $5 \mu \mathrm{m})$ column, with a guard column $(20 \mathrm{~mm} \times 4.6 \mathrm{~mm}$ id, $5 \mu \mathrm{m})$. The mobile phase acetonitrile-water mixture $(95: 5$, $\mathrm{v} / \mathrm{v})$ was prefiltered through a $0.22 \mu \mathrm{m}$ filter and the flow rate was kept at $1.0 \mathrm{~mL} \mathrm{~min}^{-1}$. The excitation and emission wavelengths of the fluorescence detector were set at 365 and $470 \mathrm{~nm}$, respectively, and the time constant was set to $2 \mathrm{~s}$. A volume of $50 \mu \mathrm{L}$ was injected for each analysis and HPLC column temperature was kept at $40^{\circ} \mathrm{C}$. The data were stored and evaluated using LC solution software (Agilent). Under the above conditions, the retention time of the abamectin was found to be $11.372 \mathrm{~min}$ (Figure 2). 
TABLE 1: Optimization of various extract solvents*.

\begin{tabular}{llccr}
\hline Spiked levels $\mu \mathrm{gg}^{-1}$ & Tea & Acetonitrile-water $(70: 30, \mathrm{v} / \mathrm{v})$ & Acetone-water $(70: 30, \mathrm{v} / \mathrm{v})$ & Methanol-water $(70: 30, \mathrm{v} / \mathrm{v})$ \\
\hline \multirow{2}{*}{0.02} & Black tea & $49.70 \pm 3.81$ & $86.40 \pm 1.43$ & $57.07 \pm 3.51$ \\
& Dried green leaves & $51.60 \pm 3.76$ & $89.03 \pm 1.68$ & $57.42 \pm 4.48$ \\
\hline \multirow{2}{*}{0.2} & Black tea & $55.38 \pm 4.48$ & $88.22 \pm 1.53$ & $66.45 \pm 5.24$ \\
& Dried green leaves & $54.79 \pm 3.62$ & $91.04 \pm 1.87$ & $67.79 \pm 4.41$ \\
\hline
\end{tabular}

${ }^{*}$ Mean of triplicate analysis \pm SD.

TABLE 2: Optimization of various adsorbents* .

\begin{tabular}{llccc}
\hline $\begin{array}{l}\text { Spiked } \\
\text { levels } \\
\mu \mathrm{gg}^{-1}\end{array}$ & Tea & Florisil & Neutral alumina & Silica gel \\
\hline 0.02 & $\begin{array}{l}\text { Black tea } \\
\text { Dried green } \\
\text { leaves }\end{array}$ & $86.40 \pm 1.43$ & - & - \\
\hline 0.2 & $\begin{array}{l}\text { Black tea } \\
\text { Dried green } \\
\text { leaves }\end{array}$ & $89.03 \pm 1.68$ & - & - \\
\hline
\end{tabular}

${ }^{*}$ Mean of triplicate analysis \pm SD.

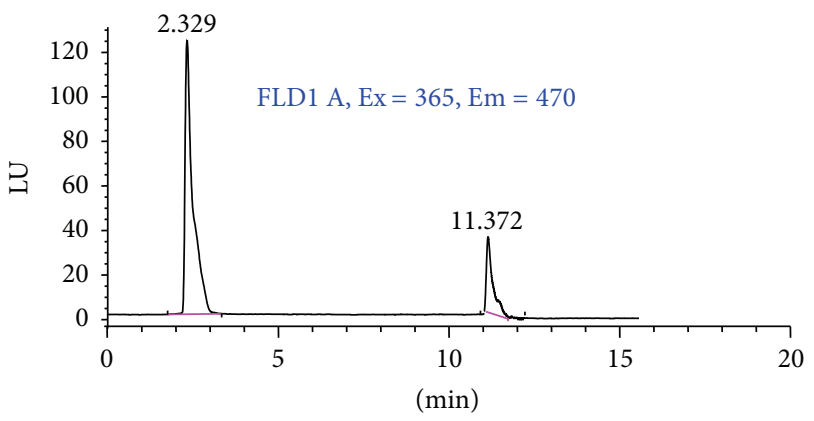

FIGURE 2: HPLC chromatogram of abamectin (reference).

\section{Results and Discussion}

3.1. Optimization of Extraction Procedure. Various solvents, including acetonitrile [6], acetone [7], and the mixture of acetonitrile and hexane [8], have been extensively used for extracting abamectin residues from various samples. But in the present study, acetonitrile-water $(70: 30, \mathrm{v} / \mathrm{v})$, methanolwater $(70: 30, \mathrm{v} / \mathrm{v})$, and acetone-water $(70: 30, \mathrm{v} / \mathrm{v})$ mixtures are used as solvents for the extraction of spiked samples of tea ( 0.02 and $0.2 \mu \mathrm{g} \mathrm{g}^{-1}$ fortification level). The efficiency in percentage of the extraction of abamectin by various extraction techniques mentioned above (Table 1 ), the best recoveries are achieved using acetone-water $(70: 30, \mathrm{v} / \mathrm{v})$ [9].

3.2. Optimization of Clean-Up Procedure. The residues after concentration are subjected to column clean-up with different adsorbents to optimize the cleanup procedures. Chromatographic columns (glass, $60 \times 1.5 \mathrm{~cm}$ id) with $10 \mathrm{~g}$ of different adsorbents like neutral alumina, florisil, and silica gel guarded with $1 \mathrm{~cm}$ anhydrous sodium sulphate are employed. Each column is prewashed with $30 \mathrm{~mL}$ of DCM.

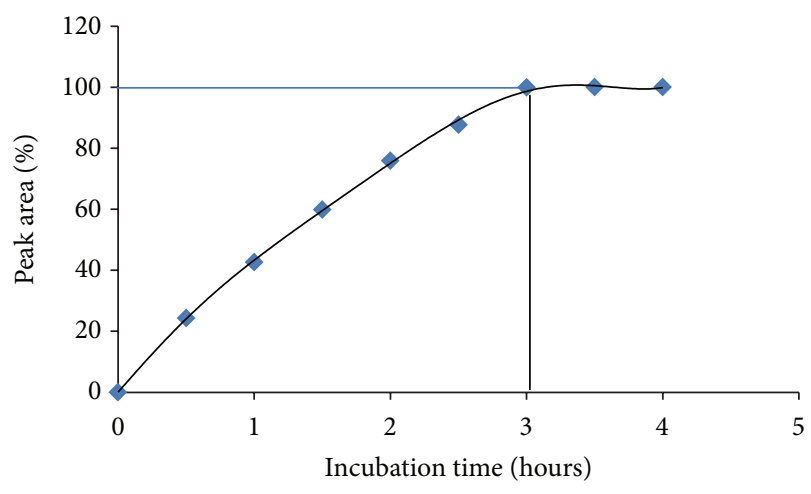

FIGURE 3: Optimization of fluorescence derivatization.

The concentrate obtained is dissolved in $5 \mathrm{~mL}$ of DCM and transferred to the column. The column is eluted with $150 \mathrm{~mL}$ of acetone and chloroform $(1: 1, \mathrm{v} / \mathrm{v})$ mixture. The final elute from each column is concentrated to dryness using a rotary evaporator. Each cleanup is performed in triplicate with a control for each set. From the results (Table 2), it is evident that florisil guarded with anhydrous sodium sulphate is an appropriate adsorbent for clean-up process in the quantification of abamectin residues present in tea.

3.3. Optimization of Fluorescence Derivatization Procedure. A combination of trifluoroacetic anhydride (TFAA) and 1methylimidazole (1-MIM) cited in the literature is chosen as the derivatizing reagents in this study also. This derivatizing reagents could react rapidly with compound and form a strong stable fluorescent derivative. However, data about the optimal experimental conditions are rather inconsistent in the literatures. The main factors affecting the derivatization are incubation time, temperature, and light [3]. Sher et al. studied the derivatives of abamectin, doramectin, moxidectin and ivermectin at $60^{\circ} \mathrm{C}$ increased compared with $25^{\circ} \mathrm{C}$ in dark condition [10]. The effect of the incubation time on derivatization is investigated by incubating the samples at 0.5 , $1.0,1.5,2.0,2.5,3.0,3.5$, and $4.0 \mathrm{~h}$ at $60^{\circ} \mathrm{C}$ in dark. The recovery of abamectin residues is found to be high at 3.0 hours of incubation time at $60^{\circ} \mathrm{C}$ in dark (Figure 3).

3.4. Method Validation. The developed analytical method is validated for linearity, precision, recovery, specificity, LOD, and LOQ as per SANCO guidelines. 
TABLE 3: Recovery study for black tea and dried green leaves using acetone-water mixture $(70: 30, \mathrm{v} / \mathrm{v})^{*}$.

\begin{tabular}{lccc}
\hline Sample & Spiked level $\left(\mu \mathrm{gg}^{-1}\right)$ & Recovery \% & RSD \% \\
\hline \multirow{3}{*}{ Black tea } & 0.02 & 86.50 & 1.93 \\
& 0.2 & 88.69 & 1.61 \\
\multirow{3}{*}{ Dried green leaves } & 2.0 & 103.84 & 0.49 \\
& 0.02 & 98.00 & 1.07 \\
& 0.2 & 92.78 & 1.22 \\
& 2.0 & 93.19 & 1.14 \\
\hline
\end{tabular}

${ }^{*}$ Mean of triplicate analysis \pm SD.

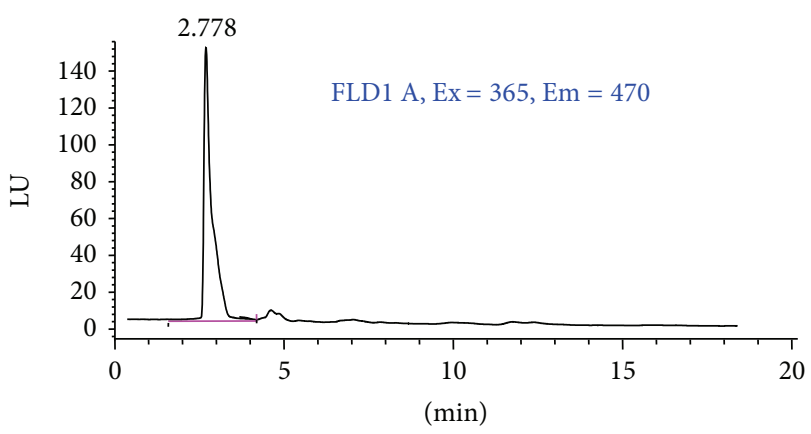

FIGURE 4: HPLC chromatogram for blank tea sample.

3.4.1. Linearity. Calibration curve is constructed by performing a linear regressive analysis with the chromatographic peak area versus the concentration of abamectin $(0,0.01,0.02,0.05$, $0.1,0.2,0.3,0.4,0.5$, and $\left.1.0 \mu \mathrm{g} \mathrm{mL}^{-1}\right)$. Each concentration is injected in five replicates. The calibration curve shows excellent linear relationship with a mean correlation coefficient $\left(r^{2}\right)$ of 0.9971 .

3.4.2. Limit of Detection. Different standards of decreasing concentration are prepared and injected in succession. The detected concentration by the instrument with $\mathrm{S} / \mathrm{N}$ at $3: 1$ ratio is taken as the limit of detection and it is estimated as $0.01 \mu \mathrm{g} \mathrm{g}^{-1}$ of abamectin.

3.4.3. Precision. The repeatability of the instrument is determined by injecting the standard solution $\left(0.3 \mu \mathrm{g} \mathrm{L}^{-1}\right)$ five times and the RSD value for the peak areas is found to be $0.92 \%$.

3.4.4. Specificity. There is no interference between the components of solvent used for the preparation of reference standard, mobile phase, test substance, and blank extract from the matrix (chromatogram presented in Figures 2 and 4). Thus the specificity of the method is established for the analyte.

3.4.5. Recovery. Recovery studies in black tea/dried green leaves are conducted by fortifying the control samples at different concentrations, namely, $0.02,0.2$, and $2.0 \mu \mathrm{g} \mathrm{g}^{-1}$ with abamectin standard solution. The samples are extracted with acetone-water mixture $(70: 30, \mathrm{v} / \mathrm{v})$, partitioned, cleaned up, and analyzed for abamectin content as described above. The

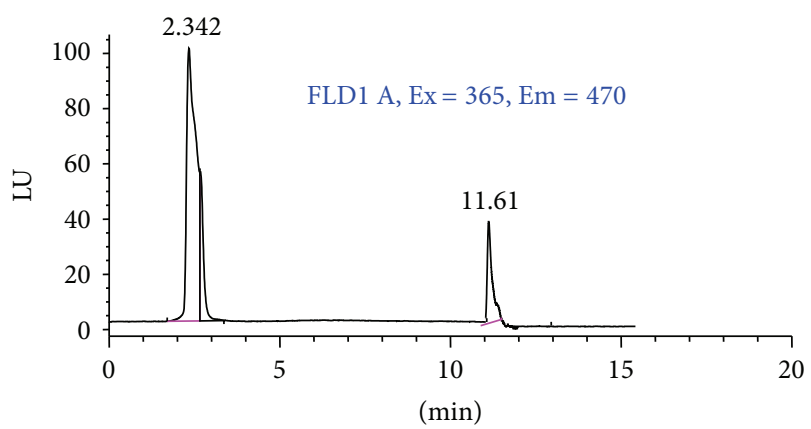

FIgURE 5: HPLC chromatogram for blank tea sample spiked at $0.2 \mu \mathrm{gg}^{-1}$.

recovery percentage ranges from 86.5 to $103.8 \%$ and 92.7 to $98.0 \%$ for black tea and dried green leaves, respectively (Table 3). This indicates that the extraction with acetonewater $(70: 30, \mathrm{v} / \mathrm{v})$ mixture is able to extract analytes from samples completely and the analyte loss is negligible during the whole analytical procedure (Figure 5).

3.4.6. Limit of Quantification. The detected concentration by the instrument with $\mathrm{S} / \mathrm{N}$ at $10: 1$ ratio is taken as the limit of quantification and it is estimated to be $0.02 \mu \mathrm{g} \mathrm{g}^{-1}$.

\section{Conclusion}

Study on the determination of abamectin residues present in the tea based on HPLC technique reveals the following conclusion. Good recovery was achieved with the extraction mixture of acetone-water $(70: 30, \mathrm{v} / \mathrm{v})$, next separation with florisil adsorbent, and a fine fluorescent derivatisation with 3-hour incubation at $60^{\circ} \mathrm{C}$ in dark. The optimized conditions are good enough to detect up to $0.02 \mu \mathrm{gg}^{-1}$ (EU MRL) of abamectin residues present in different varieties of tea.

\section{Conflict of Interests}

The authors have declared no conflict of interests.

\section{Acknowledgment}

The authors are grateful to Dr. P. Mohan Kumar, Director, UPASI Tea Research Institute, Valparai, for providing the required facilities for this study and permission to publish this research work.

\section{References}

[1] B. Radhakrishnan, J. Durairaj, S. Mathew et al., "Performance of south Indian tea industry during last one decade and challenges ahead," Bulletin of UPASI Tea Research Foundation, vol. 56, pp. 3-15, 2012.

[2] Y. Sun, X. Diao, Q. Zhang, and J. Shen, "Bioaccumulation and elimination of avermectin $\mathrm{B}_{1 a}$ in the earthworms (Eisenia fetida)," Chemosphere, vol. 60, no. 5, pp. 699-704, 2005. 
[3] X. Xie, X. Wang, and L. Zhao, "A fast, simple, and reliable high-performance liquid chromatography (HPLC) method for determining abamectin residues in vegetables and fruits," Food Analytical Methods, vol. 4, no. 2, pp. 203-211, 2011.

[4] A. I. Valenzuela, D. S. Popa, M. J. Redondo, and J. Mañes, "Comparison of various liquid chromatographic methods for the analysis of avermectin residues in citrus fruits," Journal of Chromatography A, vol. 918, no. 1, pp. 59-65, 2001.

[5] K. Yoshii, S. Ishimitsu, Y. Tonogai, K. Arakawa, H. Murata, and H. Mikami, "Simultaneous determination of emamectin, its metabolites, milbemectin, ivermectin and abamectin in tomato, Japanese Radish and tea by LC/MS," Journal of Health Science, vol. 50, no. 1, pp. 17-24, 2004.

[6] J. Hernández-Borges, L. M. Ravelo-Pérez, E. M. HernándezSuárez, A. Carnero, and M. A. Rodríguez-Delgado, "Analysis of abamectin residues in avocados by high-performance liquid chromatography with fluorescence detection," Journal of Chromatography A, vol. 1165, no. 1-2, pp. 52-57, 2007.

[7] K. Yoshii, A. Kaihara, Y. Tsumura, S. Ishimitsu, and Y. Tonogai, "Liquid chromatographic determination of emamectin, milbemectin, ivermectin and abamectin in crops and confirmation by liquid chromatography-mass spectrometry," Journal of Chromatography A, vol. 896, no. 1-2, pp. 75-85, 2000.

[8] S. V. Prabhu, R. J. Varsolona, T. A. Wehner, R. S. Egan, and P. C. Tway, "Rapid and sensitive high-performance liquid chromatographic method for the quantitation of abamectin and its delta 8,9-isomer," Journal of Agricultural and Food Chemistry, vol. 40, no. 4, pp. 622-625, 1992.

[9] K. Madasamy and V. A. Shanmugaselvan, "Determination and residues levels of emamectin benzoate in tea using HPLC with fluorescence detection," Food and Public Health, vol. 2, no. 2, pp. 12-15, 2012.

[10] A. M. Sher, S. Tung, G. E. McLeroy, and E. T. Phillipo, "Simultaneous determination of eprinomectin, moxidectin, abamectin, doramectin and ivermectin in beef liver by LC with fluorescence detection," Journal of AOAC International, vol. 83, no. 1, pp. 3137, 2000. 

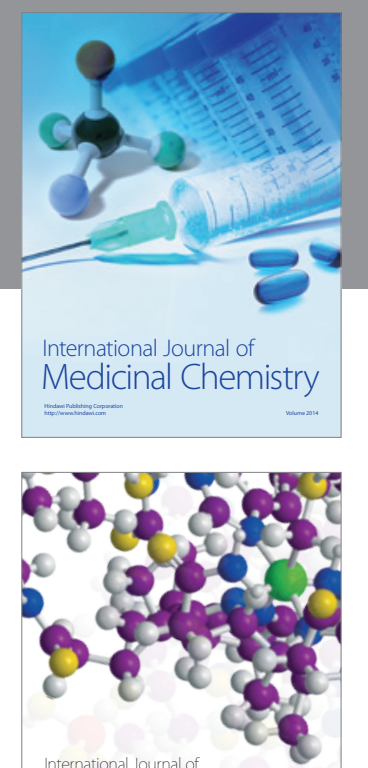

\section{Carbohydrate} Chemistry

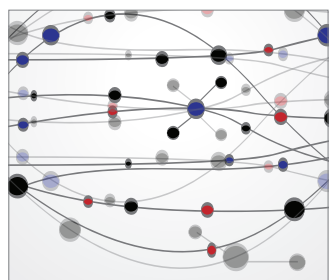

The Scientific World Journal
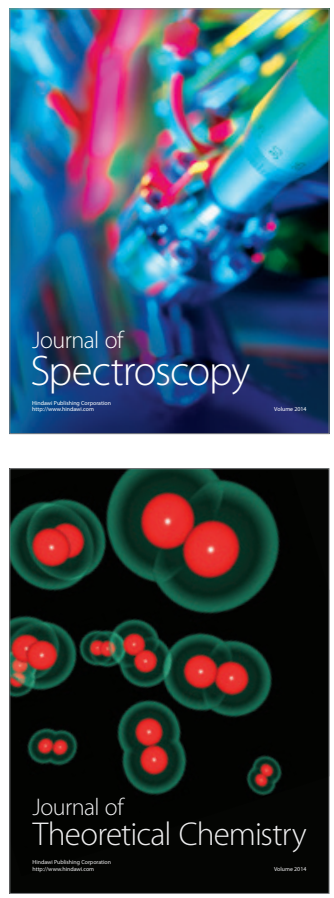
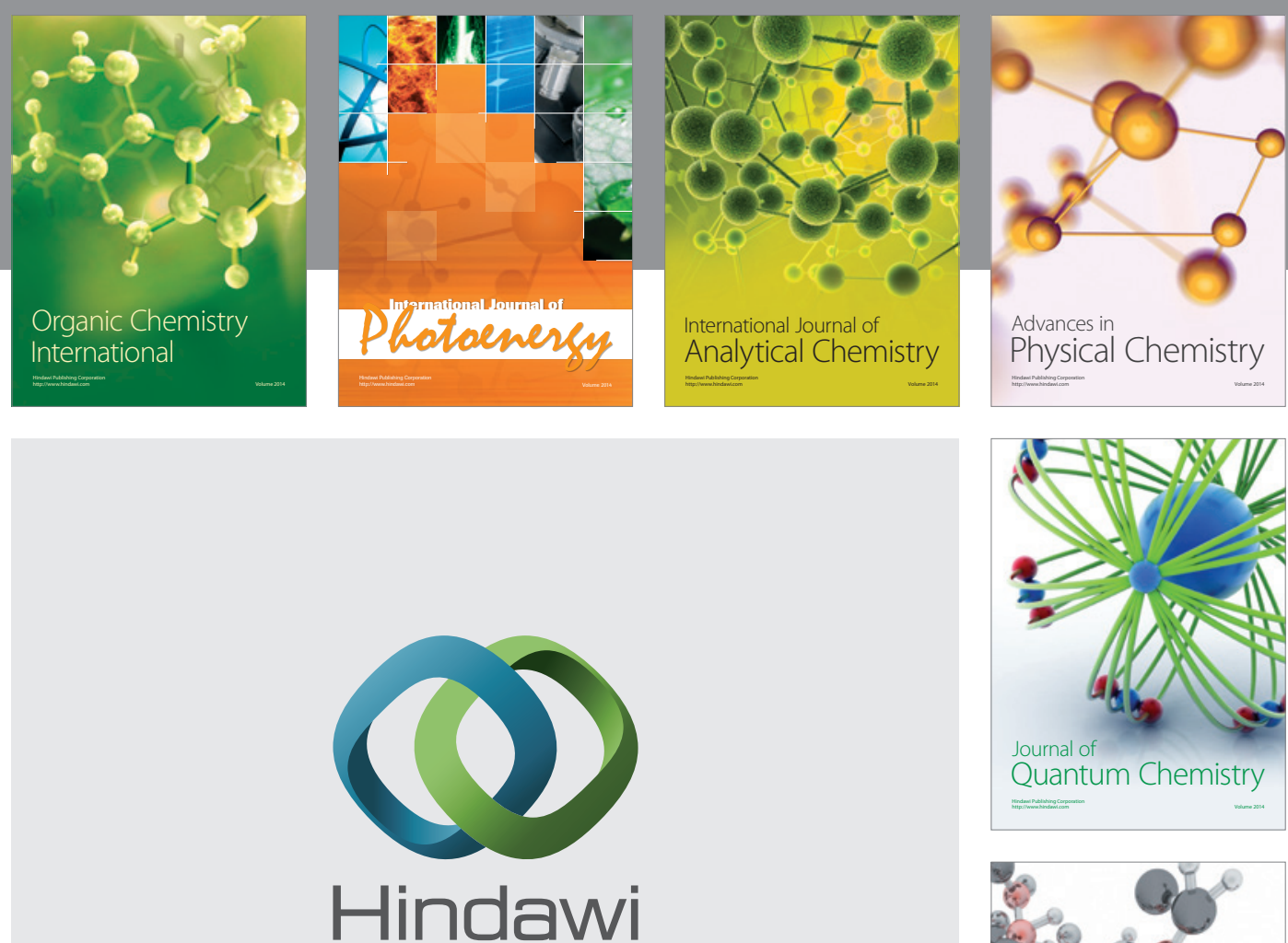

Submit your manuscripts at

http://www.hindawi.com

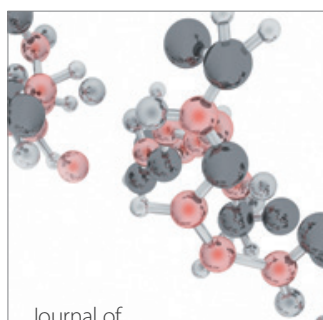

Analytical Methods

in Chemistry

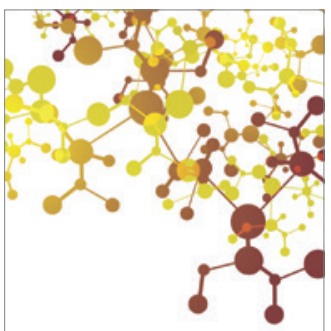

Journal of

Applied Chemistry

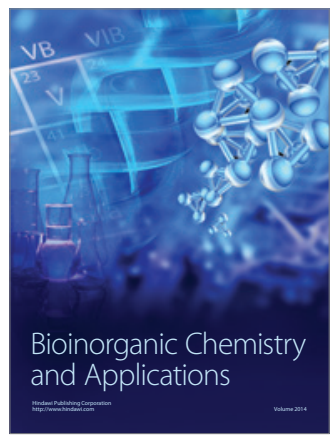

Inorganic Chemistry
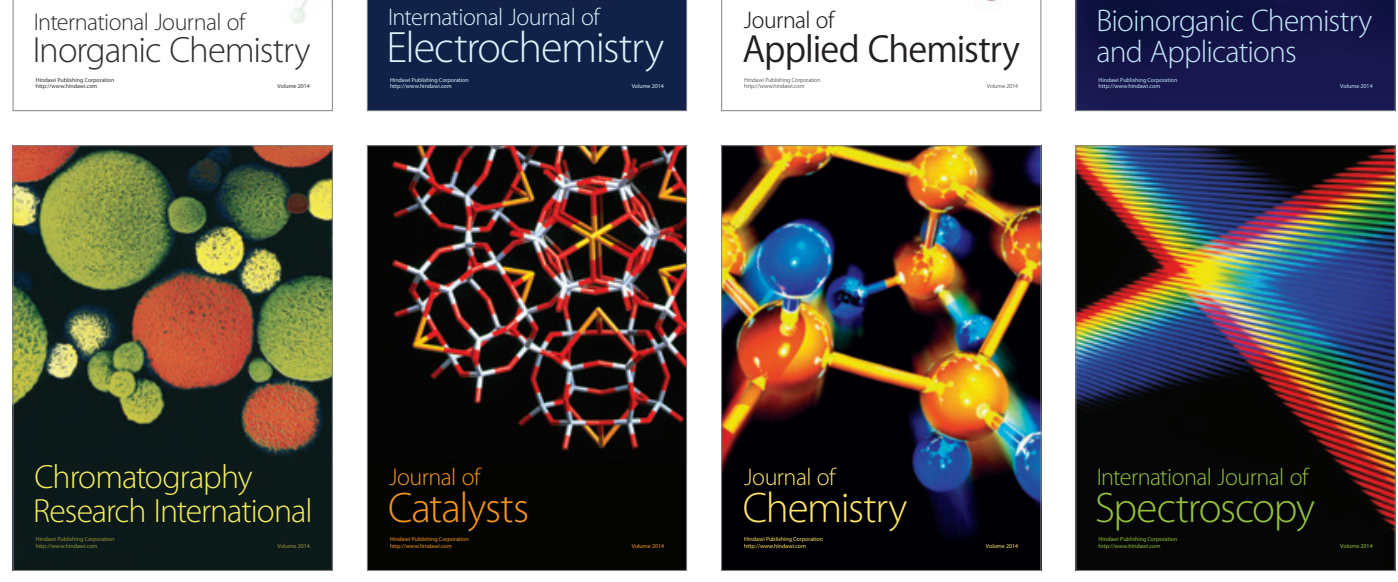